\title{
2003 California Health Framework Available Now
}

\author{
Jeri Day \\ California Department of Education, School Health Connections
}

\begin{abstract}
The 2003 Health Framework for California Public Schools was adopted by the State Board of Education on March 6, 2002. This edition includes the content of the 1994 Framework while updating information on curriculum development, health literacy, positive asset development among youth, research-based programs, school safety, and special populations.

(C) 2003 Californian Journal of Health Promotion. All rights reserved. Keywords: K-12 curriculum, health framework, CDE, public schools
\end{abstract}

The 2003 Health Framework for California Public Schools was adopted by the State Board of Education on March 6, 2002, and is now available for purchase through CDE Press. This edition includes the content of the 1994 Framework (CDE, 1994) while updating information on curriculum development, health literacy, positive asset development among youth, research-based programs, school safety, and special populations. See Appendix A for cover.

Fundamental to the education of all students is the need to have the knowledge and skills today, so that they will make good decisions about their future health and well being. Educating children at an early age about the benefits and risks of certain behaviors can lessen the impact of these risk factors and reduce their resulting burden of disease.

An important characteristic of the original 1994 framework was its emphasis on improving student knowledge and skills in order to bring about positive behaviors. The 2003 Health Framework continues to support, emphasize, and clarify the knowledge, skills and behaviors expected of students as stated in the "GradeLevel Emphases" chart at the end of "Chapter 3: Health Education.” This chart takes content found in the earlier pages under "Expectations and Content" and suggests certain topics be emphasized at specific grade levels. These specifications give greater guidance to teachers and allow for better grade-level articulation. This chart provides both clarity and relief to teachers, because it presents the skills before and after each grade, thus creating a point of reference for instruction and division of labor among teachers at each grade level. Teachers will know which topics to teach, how much to teach, and which materials support instruction at the different grades. For example, the recent trend in childhood obesity demonstrates the need for targeted health and physical education. Students who know basic nutrition and personal health will understand that weight is a result of diet and activity; and through the use of the grade-level emphases chart, teachers can make the instructional connection. The framework provides instructional guidance on teaching students how to make sound choices for nutrition, fitness, and life long health. Physical education and health teachers are perfectly positioned to make these linkages with their students.

The new framework includes an important component of mental health that focuses on suicide prevention. The goals and objectives from the National Strategy for Suicide Prevention are presented in "Chapter 4: Beyond Health Education" and can be included in district staff development training programs. This serious issue is very real in our schools and is addressed in the 2003 Health Framework to 
provide guidance for teachers that is based on the most current and confirmed research. Other additions include information on services available to adults and children within the public mental health system.

The topic of school safety in Chapter 4 is enhanced with more discussion of the threat of school violence and its consequences. The 2003 Health Framework directs educators to new safety resources for schools and includes the Education Code requirements for site-level safety plans. The framework defines threat assessment and offers a comprehensive process for implementing a threat assessment plan.

Appendix A in the framework updates statute sections, and clarifies which codes are state mandated and which are recommended. Expired statutes have been removed, and this area of the appendix has been streamlined so that essential statutes are easier to find.

There is increased emphasis on using researchvalidated programs of instruction and incorporating data into program planning and evaluation. For example, "Chapter 1: The Vision: Health Literacy, Healthy Schools, Healthy People" suggests using the California Healthy Kids Survey along with other sources of data to help guide program development and evaluation. Another recommendation for teachers is to develop positive youth behaviors through asset development also outlined in Chapter 1. Districts and schools are given guidance on how to use data to improve programs at the end of "Chapter 2: Developing Health Literacy in the Classroom and in the School." The addition of a tool to help teachers and students evaluate the quality of web sites will offer more guidance and support for classroom instruction.
"Chapter 2: Developing Health Literacy in the Classroom and in the School," includes the six health-related behaviors identified by the Centers for Disease Control and Prevention that cause $75 \%$ of U.S. death and disability. They are 1) those that lead to intentional or unintentional injuries; 2) use of alcohol and other drugs; 3) sexual behaviors that can lead to HIV infection, other sexually transmitted diseases, or unintended pregnancy; 4) tobacco use; 5) unhealthy diet; and 6) inadequate physical activity. These unhealthy behaviors usually begin during childhood, are often linked with negative school performance outcomes, and have an impact on attendance, dropout rates, behavioral problems, involvement in school activities, graduation rates, and performance on standardized tests. These six behaviors are aligned with content area and grade level expectations.

Student health and learning are inextricably linked. While the 2003 Health Framework provides greater direction to schools and districts, it also provides information on obtaining current research, resources, and statistics. These data and educational recommendations provide compelling support for the value of coordinated school health, physical education, and health education in the school environment and curriculum. This Health Framework is a valuable tool to guide teachers, schools, and districts in the development and implementation of school health education that will significantly contribute to school reform and improvement.

The 2003 Health Framework is available for $\$ 17.50$ (plus tax and shipping and handling costs). For ordering information go to http://www.cde.ca.gov/ CDE Press. To order by phone, call 800-995-4099 and ask for Item 001574.

\section{References}

California Department of Education. (1994). Health framework for California public schools kindergarten through grade twelve. Sacramento, CA: Author. 


\author{
Author Information \\ Jeri Day \\ School Health Education Specialist \\ California Department of Education \\ School Health Connections \\ 1430 N Street Suite 6408 \\ Sacramento, California 95814 \\ E-mail: jday@cde.ca.gov
}




\section{Health Framework}

for California

Public Schools

Kindergarten Through

Grade Twelve

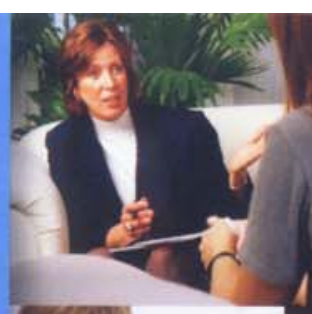

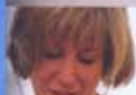
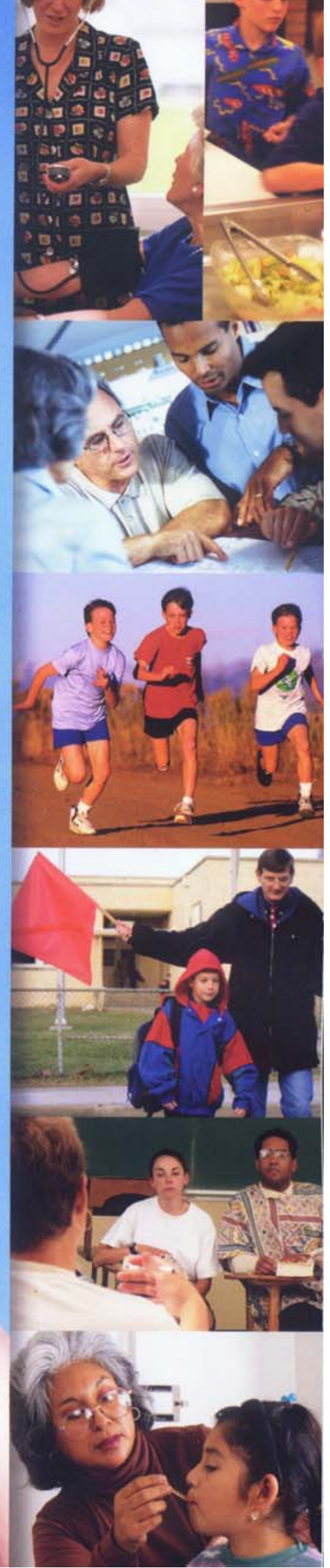